\title{
Moral intuition, good deaths and ordinary medical practitioners
}

\author{
Malcolm Parker Queensland, Australia
}

\section{Author's abstract}

Debate continues over the acts/omissions doctrine, and over the concepts of duty and charity. Such issues inform the debate over the moral permissibility of euthanasia. Recent papers have emphasised moral sensitivity, medical intuitions, and sub-standard palliative care as some of the factors which should persuade us to regard euthanasia as morally unacceptable. I argue that these lines of argument are conceptually misdirected and have no bearing on the bare permissibility of voluntary euthanasia. Further, some of the familiar slippery slope arguments against voluntary euthanasia compromise the principle of autonomy to which both supporters and opponents of euthanasia adhere. I discuss a model for doctor/patient relationships which can be applied to cases which would be seen by all disputants as strong prima facie cases for euthanasia. I argue that in certain cases it will be ordinary medical practitioners who are duty-bound to assist death.

\section{Introduction}

Despite Toulmin's idea that medicine has rescued philosophical ethics from the sidelines of practical issues, and revitalised moral philosophy towards a style of 'case morality' (1), ethics has always been practical. Meta-ethics and the concentration on meaning theory throughout the twentieth century, often criticised as dry and irrelevant, has been an important phase in the development of ethics which is now bearing fruit in many fields. However, medical ethics is a good example of how our interest in general theories can be enlivened and informed by thinking about concrete cases, even though, as I later argue, the details and the reactions to specific cases do not take us into regions where philosophical discussion ceases to be relevant.

So let us begin by considering three cases.

\section{Case 1}

An elderly couple, married over fifty years, devoted, and in frail but fair health, inform their doctor they have agreed that should either be afflicted with serious illness such that he or she could no longer live on with

\section{Key words}

Intuitions; autonomy; euthanasia; moral argument; duty. the current mobility and level of activity, then they will implement a double suicide pact; in the event of one dying, the survivor would also commit suicide. The idea of life for either without the other is unacceptable. The doctor makes no further enquiries, and his patients make no request that he take any part in these plans, even in the event that one or both become physically incapable of carrying them out.

The wife is discovered to have inoperable bowel cancer and is informed that she has no more than a few months to live in relative comfort.

Early one morning the doctor is called to attend after the discovery of both apparently dead. She is indeed dead but he is unconscious with normal respirations and heartbeat. The physical displacements of the bodies and objects in the room, together with an array of tablets and amateurish notes on overdosage and suicide, strongly suggest that they have held to their plan as outlined. The husband is dispatched to hospital where he remains unconscious and dies the following day.

\section{Case 2}

A forty-five year old man, diagnosed two years previously as having motor neuron disease, develops increasing difficulty swallowing, as well as continuing pain in his limbs and trunk at night, which considerably interferes with his sleep. There is no treatment for his condition and he has been informed of the likely end-stage of his disease, involving tubefeeding in hospital. He lives at home and spends most of his time alone, since his wife must work. He is equipped with an electric wheelchair which keeps him mobile within the home. He asks whether at the stage at which he can take no more, or when hospitalisation and tube-feeding seem imminent, someone can help him to die. It is unknown whether at such a stage, he would be capable of administering to himself drugs necessary to accomplish this or not.

\section{Case 3}

A hospitalised woman, respirator-dependent, also with motor neuron disease, requests that the respirator be disconnected. She is counselled at length by medical, psychiatric and ethicist staff. Her resolve is steadfast and her wish is complied with. She dies peacefully after being disconnected from her life-support. 


\section{Moral sensitivity and moral intuitions}

Conflicting intuitions about possible courses of action in each of the above examples will arise in many wellintentioned people. We may think, for example, that the doctor had a moral obligation to send the unconscious man to hospital, yet feel as well that considering the situation and his expressed wishes, there were good reasons to refrain from helping him, or indeed to actively hasten death. This is reinforced by the thought of what his life would have been like had he regained consciousness.

This suggests that we need to look closely at our intuitions, in order rationally to conclude about best courses of action, since without any such examination, it is just my intuition against yours, or perhaps mine against the patient's.

Opponents of euthanasia often claim that medical intuition tells against it, so this is good evidence that there may be something wrong with it (2). But of course, this is to count a value judgement as evidence, which is a circular activity, and it is to imply that there is a unanimity within the medical profession which is not supported. In their survey of doctors' practices and attitudes regarding voluntary euthanasia (3), Kuhse and Singer reported that 62 per cent of respondents approved of active assistance in death in some cases.

Gillett describes the training of doctors as involving the inculcation of a 'normative' attitude, an attitude of concern towards the suffering of patients which provides the impetus which drives the more technical activities doctors engage in (4). Having such an attitude enables the doctor to engage with patients in a way which is characterised by moral sensitivity, which is derived from personal involvement with a suffering fellow human, and which allows the doctor to form intuitions and perceptions which should be accorded special weight in moral reasoning.

The essential argument here is that this moral sensitivity is something special, something which we bring to medical ethical dilemmas in addition to our ethical formulations which are based on the facts of the case; in the case of euthanasia, it is this moral sensitivity which will make it necessary that doctors see the difference between killing and letting die.

But what more is this moral sensitivity than a certain intuition which demands the same scrutiny as any other? If our ethical formulations suggest one answer, but we still have uneasy feelings about it, this is just to say that we have conflicting intuitions, or that we have a real ethical debate on our hands. The idea of a special moral sensitivity is otiose. How else do we deliberate about cases like those described, but by a consideration of the medical facts, the wishes expressed by the patient, the consequences of the various options open, and our own positions as entrusted practitioners with an obviously close relationship with the patient? If moral sensitivity and moral competence are just the results of attention to the normative content of medical training, worthy though this practice will be generally considered, then they can say nothing substantive on either side of any issue. They will merely be the ground for our ethical formulations, which may fall either way. Being morally competent, in Gillett's sense, does not conceptually preclude any moral position, including support for voluntary euthanasia. Our moral sense cannot 'signal the inadequacy of our formulations', since our formulations presuppose having a moral sense.

So any 'pause' we feel, to use Gillett's term, when participating in terminal patient care, is just a reflection of the degree of 'ethical load' necessarily contained in those situations. For example, in case 3, when the patient requested termination of life support, her request was accorded extended consideration, she was given counselling, time for reassessment and so on, to a much greater extent than many ordinary medical requests would generate, and this is not surprising, considering the nature of the request.

Similarly, a practitioner who intuitively supports voluntary euthanasia, will still feel a pause in the dilemma depicted in case 1 , as he deliberates over his obligations to the unconscious man. His appreciation of the considerable moral content of this situation will be the ground of his careful deliberation between conflicting intuitions.

Whatever his decision, the important point is that these accounts demonstrate that a pause, or moral competence, or moral sensitivity, or any other title we give to that sense of the moral importance of the situation in hand is common to all those cases where we may be considering killing or letting die, and is present independently of and prior to any decision. So it cannot be invoked in favour of one sort of decision over the other; it cannot be used to support an alleged favoured option of medical intuition.

So it is not the case that medical intuition tells against active euthanasia, either empirically, or in the sense of a necessary normative attitude in patient care.

\section{Palliative care arguments}

In 1987, in the state of Victoria, the inquiry into options for dying with dignity (5), addressed dilemmas over patients' rights at the levels of passive and active euthanasia, and the resulting legislation, the Medical Treatment Act 1987, while refusing to endorse the latter, strongly reinforced the rights of patients like those in cases 2 and 3 above, to refuse continued treatment. Such legislative movements, while practically not giving patients any more power than the common law already guarantees, reflect the groundswell of feeling in support of patient autonomy which has gathered strength over the last two decades. They also reflect the input from a wide variety of sources within the community, many of which are nonmedical.

It is important to realise that what many groups and individuals who submit to such inquiries are concerned about is not the standard of care which is offered by a particular medical service but whether that care should continue, whether patients have the right to refuse 
treatment, and whether they have the right to die, which to be absolute must include the right to an assisted death.

Opponents of euthanasia conceal this distinction between what constitutes proper standards of medical care and what should happen when medical care has ceased to be relevant. The issue of standards of care is substituted for that of euthanasia, and is then used as an argument against euthanasia, in principle, whereas it can only be legitimately used to suggest that requests for euthanasia might decline if standards of palliative care improve. This highlights a confusion in the evaluative notion of 'proper standards of care' which opponents of euthanasia sometimes trade on.

Since 'proper standards' is clearly evaluative, it might be claimed that what is meant by proper standards is practices which do not include active euthanasia. But I will stipulate that by proper standards I mean those practices which would be generally accepted as good medical treatment of any condition prior to and independently of any decisions about killing or letting die. We can easily distinguish two senses of evaluation where there are accepted medical treatments and where there are decisions about living and dying, since these latter decisions are often taken independently of involvement in any medical setting.

The idea that sub-standard palliative care prompts calls for euthanasia may be correct in some cases, but this is not sufficient to claim, as some palliative care specialists do (6), that euthanasia is thereby called into question morally. This is because some patients will still request euthanasia where their care has been exemplary. Simply stated, decisions such as those in cases 2 and 3 have nothing conceptually to do with standards of care. Some people will continue to decide that at a certain time, whatever medicine can offer is of no further use to them, so no argument about standards of care will be relevant to such decisions. The issue of optimum standards of care, though vital, leaves something vital out, and it is of course that patient autonomy, championed by palliative caregivers in cases of letting die, requires the right to refuse treatments of whatever standards.

What are the reasons for regarding the imperative for improved standards of palliative care as an argument against the moral legitimacy of euthanasia?

The paradigm case of the terminally ill patient is the elderly patient in severe chronic pain as a result of some internal malignancy. We, the unafflicted, often regard intolerable pain as the most common reason for a request for euthanasia. But pain is one of many different symptoms which will be faced by terminally ill people, and pain relief neither renders the patient well nor changes the prognosis. But because the science of pain relief has produced very effective treatments, such that it can be reasonably said that good palliative care involves virtual pain elimination, and because we should do well what we can do well, there is a temptation to concentrate on pain relief as more important than it is. And because there are clearly deficiencies in pain relief, it is tempting to go on to claim that improvements here will not only eliminate requests for euthanasia, but render them irrational.

But pain-free patients do request euthanasia, so pain is not as centrally important as we may think.

Further, there is the feeling that we should have control over all the symptoms present, by way of drugs and support for pain, but also through good communication, sympathy and so on, for the more psychological symptoms. While opponents of euthanasia do not imagine that their support will completely remove fear and depression, it is considered that they should be effective enough to render a request for euthanasia irrational. My experience here tells me that this is quite false. Well informed and compassionately cared for patients will continue to make such requests as they do now. But the legitimacy of these requests is rejected on the grounds that care can never be qualitatively exhausted; it could always have been better, is the response, if a request is made. The request is seen as a demonstration of the deficiency of care. But surely the assessment of the adequacy of care is to be made on different grounds than this. We can, after all, assess care as adequate or not in cases where euthanasia is not requested. So the insistence on using a request as a proof of inadequate care may rest on some psychological grounds, like the unwillingness to admit to the inability to treat or cure, and the fact that a decision about the moral legitimacy of euthanasia has already been taken.

This sense of unwillingness is also shown by the insistence of those within the profession who oppose euthanasia on seeing requests for it as a great challenge for the profession (7), and on seeing the euthanasia problem as one which the profession has a mandate to solve (8).

Seeing the problem this way could only result from thinking in terms of ideals instead of realities, since it is the ideal of solving all medical problems relating to euthanasia cases which explains the need for continuing power over those situations in some form or other. But thinking in terms of ideals is no solution for current problems. Where that view is challenged it will not do to claim that the solutions lie in reinforcing those practices which, while possibly reducing slightly the number of requests for euthanasia, do not squarely address the problem of those requesters who are not complaining about their care.

I conclude that arguments about the inadequacy of palliative care are ineffective in refuting the moral legitimacy of voluntary euthanasia; indeed they say nothing about that, but reveal an uneasiness about having a presupposed moral opinion challenged.

\section{Slippery slopes}

Philippa Foot thinks that while 'there could be acts of voluntary euthanasia both passive and active against which neither justice nor charity would speak' (9), the question of legalisation brings in other difficulties, 
such as that of safeguarding against people being persuaded to give their consent, which speaks sufficiently strongly against legalisation (10).

A distinction is made between the moral permissibility of 'bare' acts of euthanasia and that of the consequences of adopting voluntary euthanasia as a matter of public policy.

Foot talks of keeping up a psychological barrier against killing (10), and Crisp argues that using doctors or nurses in assisted death may weaken the disposition of these professionals to save lives, to which end they have dedicated their careers (11). Here are slopes down which we could fall, first towards a reduced sensitivity to killing and increased convenience killings, and second towards a slackening in professional resolve to save and prolong life. Let us look at these arguments in turn.

The standard exceptions to the moral and legal proscription on killing are killings in self-defence and war. If active voluntary euthanasia is added to the list, what is the basis for thinking that our general abhorrence of killing will wilt? Why has it not already started to show signs of collapse, in a general sense? In the case of voluntary euthansia, the added safeguard of voluntariness is present which is absent even in those cases already admitted as permissible exceptions to the general proscription.

But then the aspect of voluntariness is circumvented by claiming that legalisation will run the risk of there then being people who will be persuaded to give their consent. But this turns on how we are to construe the nature of persuasion. If I am persuaded that I should go to the cinema, is it not still my decision to go? The only sense in which it is not is surely that where I am incapable of making decisions. If more people were indeed persuaded that euthanasia was an option to take, and they independently and voluntarily opted for it, what would this say? Foot fears a situation where more people might give consent to euthanasia than would choose to now; but that more people might would be a consequence of changing the law (note that it is not a necessary consequence of the change) and is not a reason not to change the law, unless other reasons are advanced in support of saying that the present situation is the best.

The idea of keeping up a psychological barrier against killing leans towards the idea that killing is intrinsically wrong, rather than prima facie wrong, and tends to limit our moral imagination in confronting situations where cases may be made for apparently counter-intuitive practices which may have beneficial consequences.

Again, if we are mindful of autonomy, we should see that fears about a climate of expectation being generated by euthanasia, whereby we may be expected to consent to being disposed of $(10,12)$, are unfounded. For if we were of sound mind, then we would voluntarily do what we feel we ought to do, and if we were not, then voluntary euthanasia would be, by definition, precluded. Further, any climate of expectation generated by the legalisation of euthanasia would be no different from that presently operating in respect of being let die. We certainly expect many competent terminally ill people to request to be let die, but then, as Ludmerer says (13), respect their choice of 'even the merest chance of life that artificial respiration or antibiotics could give them'. Climates of expectation reflect consensus attitudes but do not preclude exceptions where based on autonomous decisions of competent patients. The key concept throughout is that of autonomy, and our general expectation that we be looked after should not be affected by the prospect that voluntary requests for euthanasia will be complied with. Thus the Foot position precludes moral change despite arguing for the moral legitimacy of individual acts of euthanasia. But the specificity we can achieve through autonomy, that is the limitations we can build in to govern the legalisation of euthanasia, indicate that this distinction between individual acts and a general public policy is spurious.

Similarly, Crisp's idea that it should not be ordinary medical practitioners who bring death in response to requests for euthanasia misses some vital points about specificity and intuitions, and depends on a version of the slippery slope argument. Firstly, let us agree that, as Foot says, we already have forms of euthanasia, such as letting old moribund people die (14). Now it is contended by Crisp that we should not use ordinary medical practitioners to perform euthanasia since this would run the risk of weakening their dispositions to save lives in ordinary cases. But since saving life is as much avoided by letting die as by killing, this too should weaken dispositions to save life. But of course we do not say that, and letting die occurs daily without any worry about becoming less serious about saving life in other cases. So the idea that killing will weaken our dispositions to save lives is assumed, but should not be by the practitioner who intuitively feels the obligation to benefit all his patients, including those who request euthanasia because they are physically incapable of killing themselves.

Medical intuition does not necessarily tell against euthanasia, since we are capable of formulating complex moral principles, to take specific cases into account. Those who cannot see this process in operation fear that if euthanasia is legalised, droves of elderly people will be coerced into requests, and doctors who participate will lose their normal imperative for helping the suffering of ordinary cases. Neither claim is substantiated. Advocates of voluntary euthanasia are alert to the fact that people who request it are desperately ill. Doctors faced with an unusual request from someone who was not would be justified in inquiring deeply as to the possible psychological motivations behind the request. There is nothing to suggest that such rare requests will markedly increase once euthansia is legalised. The seriousness of the cases where euthanasia is rationally requested, and the relative infrequency of these requests suggest that doctors will easily be able to continue to regard them as 
special cases requiring special care; this special nature will prevent the blurring of distinctions which would lead to a dulling of sensitivity about saving lives.

So while it is contended that medicine is the way it is because of a moral imperative to save lives, and that sanctioning medical killing is to 'take a first tentative step from the ethical stance which has delivered to us medicine as we know it' (12), this view constitutes an intransigent naturalism which turns a blind eye to any argument which may challenge medicine to become more flexible and specific. Defenders of 'medicine as we know it' overestimate the degree by which revisionists would like to see traditional medical values change, and this is because any such change is seen as a radical value shift rather than a specific modification of a principle, (in this case the general value placed on life), which leaves the principle, as it is formulated in absolute terms, intact for the vast majority of cases.

\section{Models, acts and duties}

It is a truism that 'the physician-patient relationship is ultimately too rich, diverse, and complex to be captured by one model' (14). Different models will suit different medical encounters better than others. But some features seem necessary to all models because they are necessary features of any interpersonal relationship, where some sort of service is performed. I list these as the value element, the fiduciary element, and the element of autonomy. These three are commonly interwoven. Let us see them in operation, applied to case 2 .

People request euthanasia. In the full light of day, in control of their faculties, in the best of care, they make these requests. We are not surprised when the chairbound sufferer from motor neuron disease, who has fought his deteriorating health for three years, who fears hospitalisation and intubation, seeing these last therapeutic manoeuvres as totally pointless, asks that steps be taken to ensure that he can avoid these fearful measures. He is telling us that he is no longer able to see his life as a good. There is nothing in life for him apart from physical pain, discomfort, fear and despair. Such features are not removed by adequate analgesia, support, compassion and care; they do not reflect deficiencies in these areas. Nor do they reflect an impoverished, hedonistic view of life (12). For them to do that there would have to be a content to their lives which requesters tell us there is not.

In 'normal' medical consultations, in agreeing that a new situation should obtain, (an evaluatory element in moving from the situation of illness to that of health), the patient and the practitioner are saying together that life is worth living, since one form of it, being better, is valued more highly than another, being ill. But if we agree that such a judgement may be made, this implies the ability to judge that life, in some cases, where the reasons for life being worth living are absent, is not worth living, but it is these judgements which are ignored in refusing to take seriously, or in trying to reverse, requests for euthanasia. What we are ready to accept in the ordinary situation we are unwilling to consider in the other, although both are generically similar in that they are essentially value judgements made by autonomous agents, in respect of their own lives.

Often the treatment of a disease will simultaneously remove the threat to life and remove distressing symptoms, but this is not an absolute rule. There is no necessary connection between these two activities. Many medical services will be performed in the pursuit of cure and symptom relief where no threat to life is present. So there is no unitary purpose in medical services, such as the imperative to prolong life. The two generally recognised purposes of medicine, saving life and relieving suffering, are often independent. So in case 2, as in many others, we can be called on to do what is possible to relieve suffering, without any thought of saving or prolonging life. This is all uncontroversial.

But we are then faced with a conflict when a request is made for euthanasia, when the obligation to relieve suffering, which we have taken on in treating the patient necessitates overthrowing not just the imperative to save life but the prohibition on taking it. But we have already shown that it is inconsistent to reject autonomously made value judgements, that is, inconsistent with ordinary medical practice. So autonomy should be sufficient to override the imperative to save life while still honouring the patientphysician relationship in continuing to relieve suffering. In case 2 , relieving the suffering which can only be defined by the patient, can only be achieved through active hastening of death, however, so on a value/autonomy model, euthanasia is not only permissible, but becomes part of an obligation which has already been taken on.

It has been argued (15), that the fiduciary model of the physician-patient relationship should be preferred to others, since it avoids certain assumptions made by contractual and authoritative models about what levels of autonomy patients exhibit, and reflects that special concern for a fellow human in need on the part of the doctor. Based in this concern, certain acts of euthanasia are seen as permissible supererogatory acts, rather than as any form of duty, since it is assumed that we have every right to refuse to co-operate in such acts. But if we always retain this sort of right, it could only rest on there always being reasonable doubt about the permissibility of euthanasia, and it is this issue which is at stake. If no plausible opposition can be mounted to certain cases of euthanasia, while strong arguments can be given in their support, then the claim that we can always demur from assisting death becomes less plausible because less like some sort of foundational belief, which it is presently taken to be. That it is thus taken is the result of current consensus, not argument.

Jones points out that these acts are supererogatory because their performance in the current legal climate is legally risky, and fits this description together with a 
fiduciary model of the doctor-patient relationship as a conceptual point, rather than a moral argument. If the fiduciary model is plausible, then given the current legal situation, certain acts can be seen as supererogatory.

But if the fiduciary model is insufficient, and the value/autonomy model better suited as a generic description of the relationship, then there are grounds for claiming that while such acts are presently seen as supererogatory, they should be seen as duties, with a consequent change in the law.

To claim that the fiduciary model is sufficient is to forget that the patient initially comes to the physician in order to correct some dis-valuation in his state of health; autonomy is, at least initially, presupposed. So it is not just a fiduciary element that is brought to the relationship. (If the fiduciary model implies the presence of such other factors, then of course the models are not too dissimilar).

But we can see that the physician becomes engaged in a continuity which involves him in more than just concern for the patient. His autonomous agreement to care for the patient uncontroversially imposes 'normal duties of care' which are only arbitarily distinguished from the nature of his response when the patient autonomously disvalues the whole of his life and opts for death.

Patients themselves discern that continuity when they ask of their ordinary practitioners who have cared for them during their illness whether they will help them at the end.

While the laudable aim of rendering terminal illness manageable and acceptable remains an ideal, the real wishes of those currently suffering should be complied with, and if that is a normal part of our humanity, then we should not be praised for complying.

\section{Conclusion}

If both claims, that killing and letting die are necessarily morally equivalent, or necessarily morally different, are false (16), then their moral equivalence or difference must lie in the contingencies of each particular case. So an examination of cases should reveal whether, in each one, we can say that the difference between killing and letting die would be morally relevant. But if it is uncontroversial that both the above claims are false, this just serves to show that we must think consequentially in deliberating about each case. This is because one cannot deliberate about individual cases in any meaningful way without reference to other cases and if we are thinking about other cases we are thinking about what happened in each of them. We are therefore committed to considering the best outcome in these cases, and if we do that, we oblige ourselves to perform the action in the particular case under scrutiny which leads to that outcome. We will see that killing may lead to a better outcome than letting die in some cases (for example case 2 ), whereas it may be morally equivalent to letting die in cases like case 3 .
Objections to euthanasia are raised even by those who see that ethical formulations concerning the acts/ omissions doctrine follow this scheme, ie, those who admit that case study shows that certain acts of killing are contingently morally equivalent to acts of letting die. But in so admitting they are then committed to the possibility that other cases of killing may well be contingently morally different from cases of letting die, in the sense of being morally preferable. But they then deny this possibility. They employ either old concepts like conflicting intuitions masquerading as necessary elements of medical practice, or arguments which simply address other problems than the morality of assisted death. Slippery slope arguments preclude moral change even when the permissibility of individual acts is admitted, but trade on a false view of the degree of complexity we can achieve in our moral principles. So all possible acts of assisted death are excluded as morally impermissible, prior to their individual examination, as is a policy of legal euthanasia, even for those who cannot commit suicide. The cost is significant and unnecessary physical and mental morbidity, as well as the commitment of many to long-term fears about the nature of their deaths.

In the absence of cogent objections, we should assist death in those cases where even those who remain opposed to voluntary euthanasia admit that argument supports it. Their opposition is said now to lie in the fact that there is no clear way to capture our moral judgements by appeal to argument alone (17). But this is to miss the vital fact that our intuitions form the content of our arguments, and while we continue to hold moral views, they will be argued. To say that there are limits to philosophy in medical ethics is to say that we should stop arguing, and that is just to say that we should have no reasons for our views.

Malcolm Parker MB BS is a General Practitioner in private practice and is completing a Philosophy degree at the University of New England, New South Wales.

\section{References}

(1) Toulmin S. How medicine saved the life of ethics. In: De Marco J P, Fox R M, eds. New directions in ethics. London: Routledge \& Kegan Paul, 1986; 265-281.

(2) Gillett G. Euthanasia, letting die and the pause. Fournal of medical ethics 1988; 14:65.

(3) Kuhse H, Singer P. Doctors' practices and attitudes regarding voluntary euthanasia. Medical journal of Australia 1988; 148:623.

(4) See reference (2): 66 .

(5) Parliament of Victoria Social Development Committee. Report on the Inquiry into Options for Dying with Dignity. Second and final report. Melbourne: Government Printer, 1987.

(6) Pollard B J. Killing the dying - not the easy way out. Medical journal of Australia 1988; 149:312.

(7) See reference (6): 315 .

(8) Pollard B J. Dying: rights and responsibilities. Medical journal of Australia 1988; 149:147.

(9) Foot P. Euthanasia. In: Virtues and vices and other essays 
in moral philosophy. Oxford: Basil Blackwell, 1978: 55.

(10) See reference (9): 59.

(11) Crisp R. A good death: who best to bring it? Bioethics $1987 ; 1: 74$.

(12) See reference (2): 66.

(13) Ludmerer N. Commentary on: Twycross R G. Debate: Euthanasia a physician's viewpoint. Fournal of medical ethics 1982; 8:93.

(14) Christie R J, Hoffmaster C B. Ethical issues in family medicine. New York: Oxford University Press, 1986: 29.

(15) Jones G E. The doctor-patient relationship and euthanasia. Fournal of medical ethics 1982; 8:195-198.

(16) Gillon R. [editorial]: Euthanasia, withholding lifeprolonging treatment, and moral differences between killing and letting die. Fournal of medical ethics 1988; 14:116.

(17) See reference (2): 63.

\section{News and notes}

National Conference on Ethics Committees

A conference entitled Keeping Ethics in Ethics Committees will be held on April 5th and 6th this year at the Hershey Hotel, Philadelphia, Pa. The sponsors are the College of Physicians, The Hastings Center and the Delaware Valley Ethics Committee Network.

Registration details from Philip Boyle, Associate for Medical Ethics, The Hastings Center, $255 \mathrm{Elm}$ Road, Briarcliff Manor, NY 10510. Telephone: (914) 762 8500; Fax: (914) 7622124. 